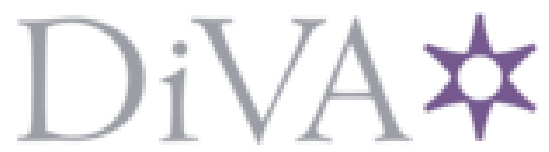

http://www.diva-portal.org

This is the published version of a paper published in Nordic Pulp \& Paper Research Journal.

Citation for the original published paper (version of record):

Heldin, M., Isaksson, P., Wiklund, U. (2016)

Initiation of wood defibration in groundwood pulping, single asperity indentation and scratching.

Nordic Pulp \& Paper Research Journal, 31(3): 401-406

Access to the published version may require subscription.

N.B. When citing this work, cite the original published paper.

Permanent link to this version:

http://urn.kb.se/resolve?urn=urn:nbn:se:uu:diva-310478 


\section{Initiation of wood defibration in groundwood pulping, single asperity indentation and scratching}

\author{
Magnus Heldin, Per Isaksson, Urban Wiklund
}

\begin{abstract}
KEYWORDS: Defibration; Scratching; Strain analysis
SUMMARY: To understand how the energy requirements of the mechanical pulping process can be reduced, the fundamental mechanisms behind fiber separation in Norway spruce were studied experimentally and analytically. Single tip scratching in heated water was used to reproduce initial defibration mechanisms found industrially. The resulting scratches were then compared with surfaces ground in a real industrial process. Moreover, the mechanical behavior of the wood microstructure was monitored with X-ray computed microtomography as a single hard tip was pressed into it. Subsequent digital image correlation was applied to estimate the strain field in the region around the indenting tip. Regions in the wood with high tensile or shear strains were identified, i.e. where cracking and fiber separation is believed to initiate.
\end{abstract}

ADDRESSES OF THE AUTHORS: Magnus Heldin ${ }^{1}$ (magnus.heldin@angstrom.uu.se),

Urban Wiklund $^{1}$ (urban.wiklund@angstrom.uu.se),

Per Isaksson² (per.isaksson@ angstrom.uu.se).

${ }^{1}$ Tribomaterials group, The Ångström Laboratory, Uppsala University, Box 534, SE-751 21 Uppsala, Sweden.

${ }^{2}$ Applied Mechanics, The Ångström Laboratory, Uppsala University, Box 534, SE-751 21 Uppsala, Sweden.

\section{Corresponding author: Magnus Heldin}

Groundwood pulping is a process with a long history, going back more than 170 years (Sjöström 1993). In this process a wood log is ground against a turning wheel with an abrasive surface. The interaction between the wood and the abrasive surface is traditionally considered to have two different effects. One is to separate the individual fibers from the wood, achieved mainly by two processes; fatigue and peeling. The other is a mechanical treating of individual fibers leading to a modification of their structure and properties, such as fibrillation, collapse etc.

A well-known fact about groundwood pulping is that it is an electric energy demanding process, where only a fraction is used to create useful pulp. Uhmeier et al. (1996) compiles results from previous studies, showing estimated efficiencies varying from $1 \%$ to $33 \%$. It has been shown that the major part of the energy losses is a result of viscoelastic deformations during the compression and relaxation of the wood structure (Atack, Tabor 1958; Steenberg, Nordstrand 1962). Undoubtedly, the tool surface is a key element in this; by the way it contacts the fibers in the $\log$ and by its subsequent action in loosening them from the wood structure. The characteristics of the grinding stone and grits have been found to have large implications on the energy requirements in relation to the final pulp characteristics
(Lucander et. al. 1985; Enström et al. 1990; Sandås, Lönnberg 1990; Sandås 1991; Lönnberg et al. 1996; Lönnberg et al. 2006; Tuovinen et al. 2009; Tuovinen, Fardim 2015), and more energy efficient grinding stones have been developed (Björkqvist, Lucander 2001; Lucander et al. 2010).

However, only limited amount of research has been made on the detailed mechanisms that govern defibration and how the tool surface affects these (Dornfeld, Wu 1977; Dornfeld 1981; Lönnberg et al. 2007; Tuovinen et. al. 2008; Karinkanta et al. 2011). Moreover, the traditional and widely used model for fiber separation, in which fatigue is a key element, has recently been scrutinized (Tuovinen et al. 2009). These two facts suggest it's time to reconsider the required modes and models for energy efficient fiber separation.

In groundwood pulping, logs of wood are ground when abrasive tips are pressed against the wood and moved perpendicular to the length of the fibers; cf. Fig 1 showing the surface of Norwegian spruce imaged in a scanning electron microscope (SEM). At the microscopic scale the industrial defibration process is stochastic. From the perspective of a specific fiber, the contacts with grinding grit occur very much at random. To study the fundamental deformation processes involved in defibration, a more controlled situation is desired. An obvious approach is to focus on a single asperity and its contact with the log surface, similar to the work by Dornfeld (1981).

Two very critical parameters are the penetration depth and the depth of influence. In this work we investigate how discrete abrasive tips interact with the log surface using controlled single asperity indentation, in-situ in an $\mathrm{X}$-ray computed microtomograph $(\mathrm{X} \mu \mathrm{CT})$, and repeated single asperity scratching at controlled conditions. Understanding these interactions is fundamental to any effort to modify the tool geometries to optimize the defibration process. Although contact with discrete tips is quite far from a defibration process, different forms of single tip experiments can hint at what potential lies in tailoring the abrasive tips for decreased energy consumption during defibration.

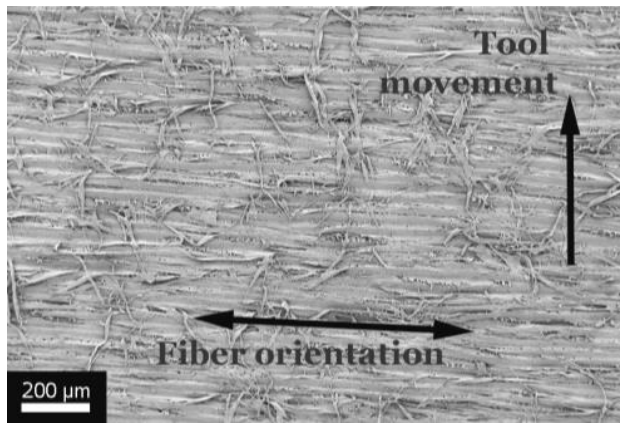

Fig 1 - Wood surface imaged in SEM, with fiber orientation and tool movement indicated. 


\section{Methods}

Norway spruce (Picea abies) obtained from a Swedish pulp mill has been used in this work. The fibers in the samples had diameters ranging from $5 \mu \mathrm{m}$ (latewood) to $40 \mu \mathrm{m}$ (earlywood). For indentation, samples about $5 \times 5 \times 4 \mathrm{~mm}$ were prepared and for scratching, the dimensions were $20 \times 15 \times 3 \mathrm{~mm}$. The samples were prepared by cutting and grinding with 500 and 1200 grit silicon carbide grinding paper with water lubrication.

From the same pulp mill, a log piece that had only been partly ground was also extracted. Its surface offers a snapshot of the as-ground state from within the industrial milling process. It thus allows comparisons between the ground industrial surface and the single asperity scratched surfaces produced in this work. In addition, a pulp sample extracted right after the grinding stage was also collected to study the morphology of the freshly separated pulp fibers.

\section{Indentation and tomography}

$\mathrm{X}$-ray computed microtomography $(\mathrm{X} \mu \mathrm{CT})$ is a nondestructive technique to measure material density throughout a volume. It is ideally suited to obtain quantitative information of wood. The equipment used, a SkyScan-1172, has a resolution high enough to image and measure individual fibers and fiber fragments. The instrument has a built-in compression stage, which was used to press a small indenter into a wood specimen. The indenter, made of steel, was needle shaped with a $200 \mu \mathrm{m}$ radius spherical tip. $200 \mu \mathrm{m}$ is similar to the radius of asperities in industrial grinding stones, although these are seldom spherical (Tuovinen et al. 2013). The compression stage is mounted on a slowly rotating holder that allows X-rays to enter from different directions. In this way, two-dimensional projection images were taken in a multitude of directions, which allow subsequent reconstruction of a 3D microstructure. The penetration of the tip into the wood sample was stepwise increased from 0 to $50 \mu \mathrm{m}$, allowing for successive 3D images showing the complete deformation process when the indenter penetrates the wood. During each scan, 998 radiographs with an acquisition time of $8 \mathrm{~s}$ each were taken over 180 degrees with a pixel size of $2.44 \mu \mathrm{m}$.

\section{Full field strain analysis}

The strain field in the indented wood was estimated using digital image correlation (DIC) techniques on crosssections of reconstructed 3D X $\mathrm{CCT}$ images. The crosssection selected was the radial-tangential plane, i.e. a plane showing the cross-section of fibers, in which the center of the indenter was moving, cf. Fig 2. Then, comparing cross-section images at different penetration depths, 2D coordinates of the deformed wood internal surfaces were calculated by a 2D digital image correlation algorithm (Blaber et al. 2015). For most materials analysed in this way, a random or regular pattern, which deforms along with the specimen, must be applied to the specimen surface. However, for wood materials there is no need for this thanks to the inherent pattern in the wood's microstructure. The random variations in density and thickness of cell walls are a sufficient reference pattern. The deformation of an approximately $2 \times 2 \mathrm{~mm}$ domain in the indented wood was used for the calculations. Then, from the correlation procedure, a complete displacement field is obtained. By numerical spatial differentiation of the displacement field an approximation of the strain field is determined.

\section{Scratching}

Scratch testing was made using a CSM Revetest, equipped with three different diamond styli. All three were sphero-conical with a cone angle of $120^{\circ}$, but with different sphere radii; 50, 200 and $500 \mu \mathrm{m}$ respectively. To resemble the wet conditions in the industrial defibration process, the samples were submerged in water during scratching. Moreover, both water at $20^{\circ} \mathrm{C}$ and $95^{\circ} \mathrm{C}$ were used. In a pulp mill, the processes take place at an elevated temperature in steam environment. Water at $95^{\circ} \mathrm{C}$ represents a similar, although unpressurized, environment, whereas water at $20^{\circ} \mathrm{C}$ serves to study the process without any heating. Scratching was made with a nominal load set very low, $2 \mathrm{~N}$, but varied between 2 and $3 \mathrm{~N}$ during the scratch due to the inhomogeneous structure of the wood samples. Each scratch was performed at a speed of $40 \mathrm{~mm} / \mathrm{min}$ and made $20 \mathrm{~mm}$ long. As defibration in the groundwood process relies on multiple contacts with a specific fiber before it separates from the wood, scratching was also conducted multiple times in the very same track, 3, 10 or 20 times. The tracks were imaged and analyzed in an SEM after the surfaces were dried, and coated with a gold/palladium alloy to prevent charging.

\section{Results}

\section{Strain analysis}

Both shear and compressive stresses act in the region below the tip as shown in the reconstructed cross-sections from $\mathrm{X} \mu \mathrm{CT}$, see Fig 3. The white area in the upper part is the indenter having penetrated a small distance into the wood. Superimposed are contours of the estimated inplane strain fields first principal normal strain $\varepsilon_{1}$ and principal shear strain $\gamma 1$ (normalized with their highest values, $\varepsilon_{0}$ and $\gamma_{0}$ ) and the volumetric strain $\varepsilon_{\mathrm{vol}}$ given by the trace of the normal strain components.

For comparison, the corresponding strain contours of classical theoretical Hertz strains (Johnson 1985) in an isotropic elastic continuum are shown in Fig 4.

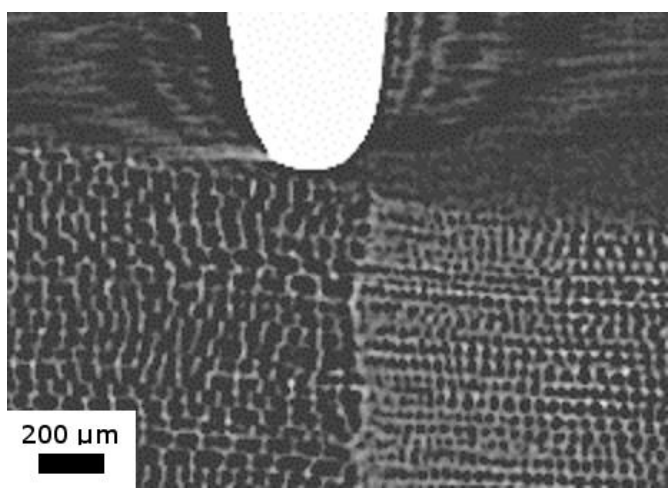

Fig 2 - A reconstructed cross-section image of wood, using $\mathrm{X \mu CT}$. The white object, close to the wood surface, is the tip. 
Both experimental and theoretical strains are for an indentation depth of $50 \mu \mathrm{m}$, roughly corresponding to one fiber diameter. This means that the stress state in the wood most likely remained in a linear elastic regime while keeping the influence from nonlinear deformations caused by plasticity or damage low.

Comparing the experimental and theoretical strains lend some interesting observations. Even though the penetration depth is low, the magnitudes of experimental strains are high at relatively large distances from the tip. The classical purely linearly elastic Hertz strain fields have considerably higher gradients and the regions of high strain are located substantially closer to the tip. Both experimental and theoretical strains have regions where they are positive, i.e. tensile. However, in wood those regions are substantially larger and located in diffuse zones some distance away from the contact close to the surface, indicating that mode I cracks, or separation of fibers, can most likely be opened at a shallow depth around the tip. The theoretical Hertz strain field, on the other hand, has tensile strain in narrow regions at the very contact edge.

The region of relatively high experimental shear strains is larger, compared to the theoretical field, and located at a distance more than two times deeper down in the material. Thus, the strain field in the wood material is somewhat different than in an ideal elastic homogeneous continuum. Moreover, at the cell level, a combined compressive and shear load can produce shear (mode II) cracks via breaking of cell walls. If the confining pressure is so high that an opening of a crack is prevented, the continued crack growth will occur along the plane of principal shear stress (Isaksson, Ståhle 2002). These observations indicate that the material's complex cellular microstructure alters the mechanical field on a global scale. This is not surprising because wood is a highly heterogeneous material with relatively large internal material-characteristic lengths (i.e. cell sizes). The cell walls distribute forces in the microstructure in a complex manner resulting in an altered deformation field as compared to a classical continuous material, meaning that traditional continuum theories are not accurate enough to describe indentation or scratching in wood materials because their lack of length scales.

\section{Scratching}

Fiber separation and curling of fibers can be seen in all three scratches made in water at $95^{\circ} \mathrm{C}$ as shown in Fig 5, where 10 scratches have been made at each position with a tip with 50, 200 or $500 \mu \mathrm{m}$ radius. Fiber separation and curling are most dominant in the scratch from the stylus with the smallest radius. As the stylus tip radius was increased, the drastic fiber separation and fiber fracture was changed into mostly deformation and only minute cracking along the length of the fibers. Scratching using the same parameters, but at a water temperature of $20^{\circ} \mathrm{C}$, concentrated the deformation to the center of the track, cf. Fig 6. The amount of fiber separation is lower but the permanent fiber deflection remaining close to the center of the track is higher. The number of scratches increased both the separation between fibers and the fiber fracture as shown in Fig 7. In these images, a $50 \mu \mathrm{m}$ stylus has been used to make different number of scratches, all at the very same position, at a water temperature of $95^{\circ} \mathrm{C}$.

The wood sample that had been ground in the industrial process showed extensive curling and twisting of partly separated, but still attached, fibers as shown in Fig 8. The morphology of fibers separated in the same process, showed some largely intact fibers but also numerous fragments in the form of fibrills when imaged in an SEM, cf. Fig 9.

\section{Discussion}

\section{Strain analysis}

In a wood structure, the region of high shear stress, where shear mode fracture may initiate and grow despite a confining pressure, is located deeper down in the material than what is anticipated from classical continuum theories (Hertz).
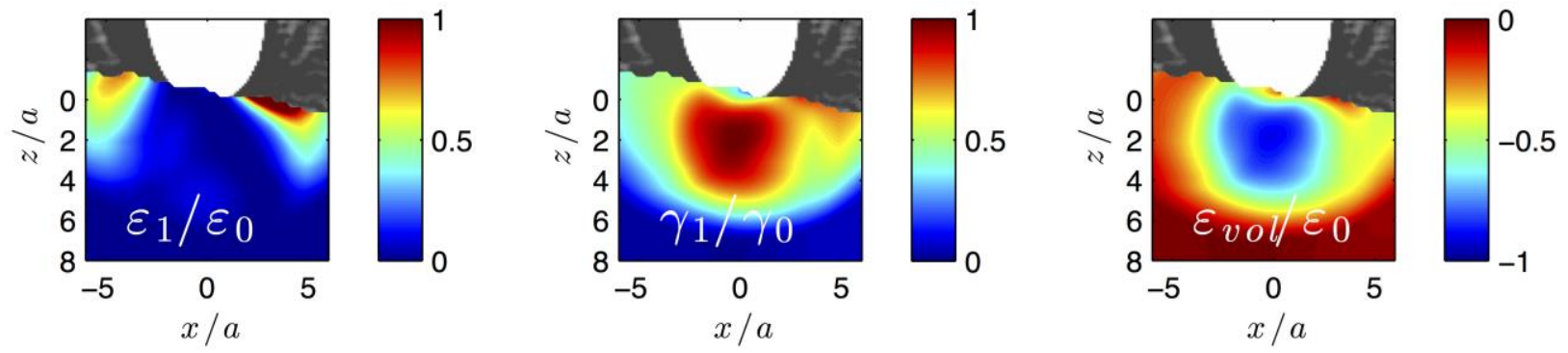

Fig 3 - DIC-estimated principal and volumetric strains in indented wood. $a$ is the contact radius.
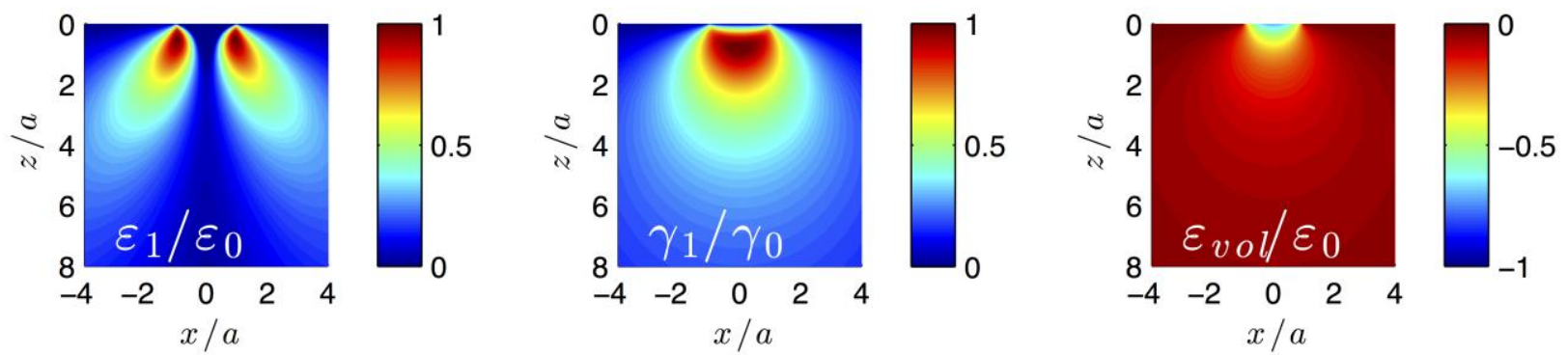

Fig 4 - Principal strains according to the classical Hertz elasticity theory. $a$ is the contact radius. 


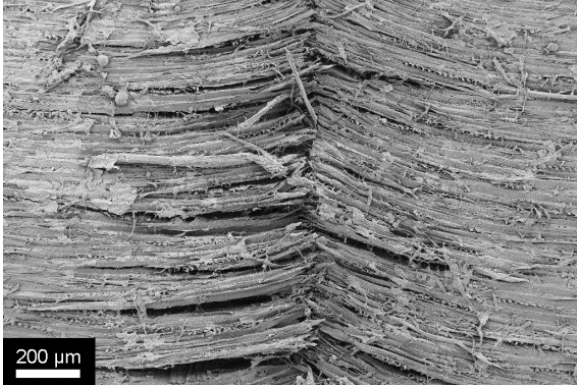

(a)

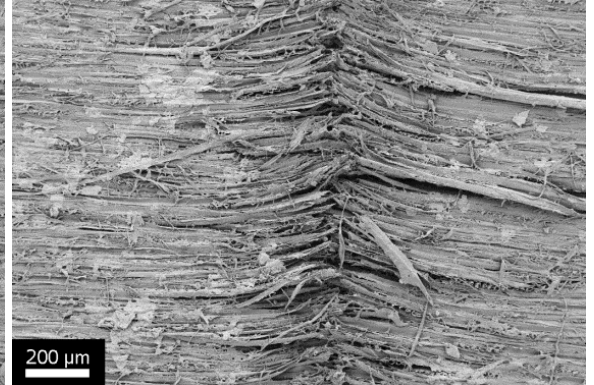

(b)

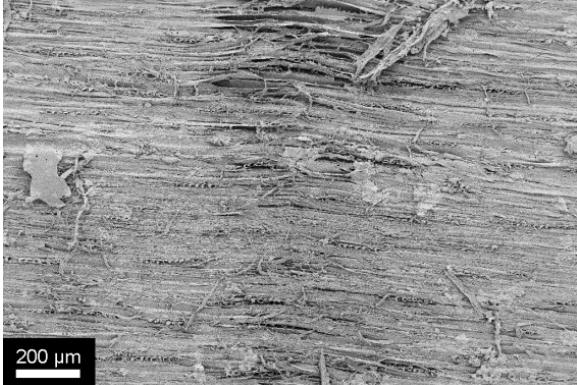

(c)

Fig 5 - Scratches made using different styli, (a) $50 \mu \mathrm{m}$, (b) $200 \mu \mathrm{m}$ and (c) $500 \mu \mathrm{m}$. A water temperature of $95^{\circ} \mathrm{C}$ was used and 10 repeated scratches were made in the same track.

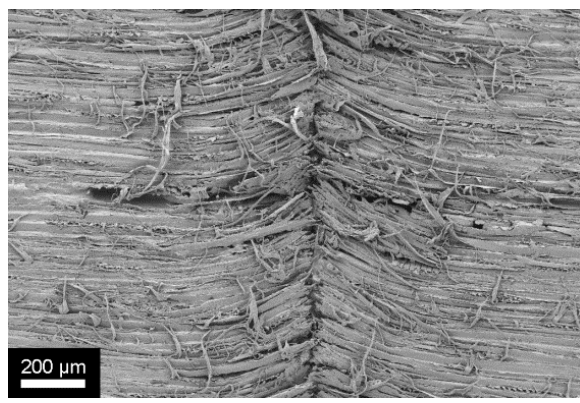

(a)

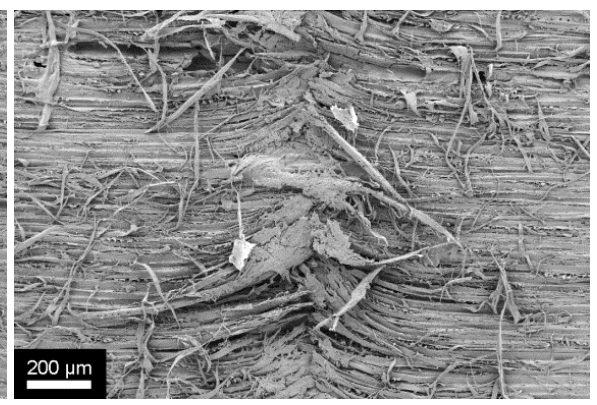

(b)

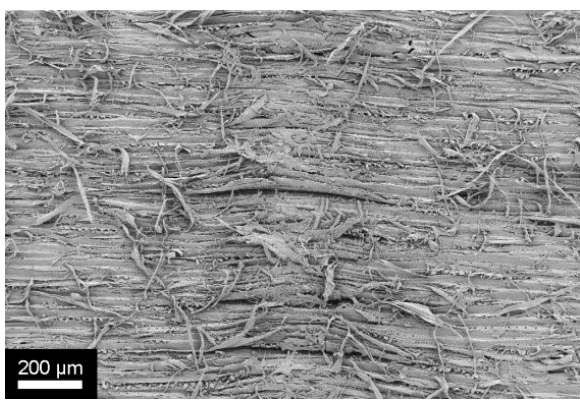

(c)

Fig 6 - Scratches made using different styli, (a) $50 \mu \mathrm{m}$, (b) $200 \mu \mathrm{m}$ and (c) $500 \mu \mathrm{m}$. A water temperature of $20^{\circ} \mathrm{C}$ was used and 10 repeated scratches were made in the same track.

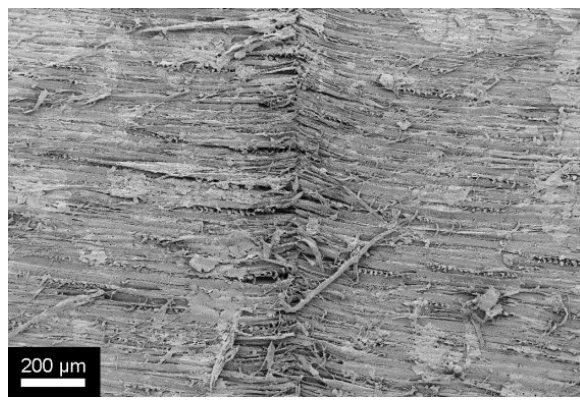

(a)

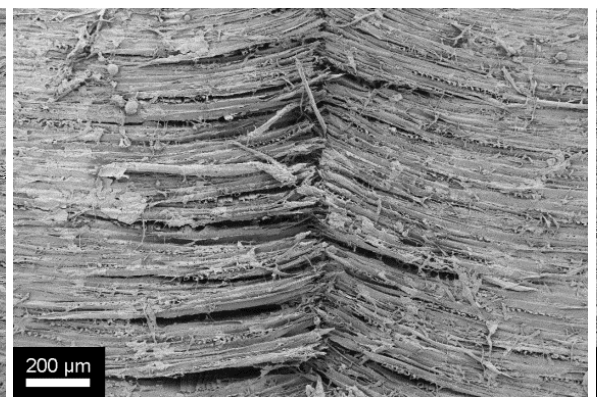

(b)

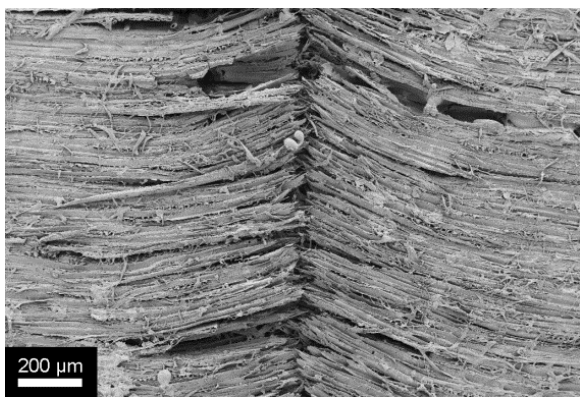

(c)

Fig 7 - Scratches made using a $50 \mu \mathrm{m}$ radius stylus but the number of repeated scratches are different, a) 3, b) 10, c) 20 . The wood was submerged in water with a temperature of $95^{\circ} \mathrm{C}$.

This would mean that crack initiation is likely to occur at depth below a number of cell layers, and in a fairly large region, which would lead to eventual removal of blocks of cells which are not separated into individual fibers but more like bundles. If crack initiation and growth closer to the surface is desired, to promote direct separation into individual fibers, both tool geometry and penetration depth must obviously be taken into account. This observation implies that the mechanical characteristics of the microstructure have to be included in order to obtain accurate results and to optimize the defibration process. It is in the regime of some microns that classical continuum theories do not suffice for an accurate and detailed description of corresponding deformation phenomena in wood, cf. Figs 3-4. Obviously, fundamental material structural effects, such as those of cells and cell walls, cannot be captured by standard elasticity theories even though such effects become dominant as the specimen or component size decreases or when defect sizes are of the same order as the materials' characteristic structural lengths. Importantly, "unphysical" mathematical elastic singularities as those emerging during the application of point load indentation cannot be removed. Roughly speaking, the inability of standard continuum mechanics theories to deal with mechanical problems in heterogeneous materials such as wood is due to the absence of internal lengths, characteristic of the underlying microstructure, in the constitutive equations. More sophisticated methods have to be applied, such as highdensity finite element models or gradient-enhanced continuum theories (Isaksson, Hägglund 2013).

\section{Scratching}

The large influence of tip radius on scratching is interesting. As seen in Fig 5, the fiber separation was dramatic when using the stylus with the smallest radius but smaller when using the stylus with largest radius. According to the $\mathrm{X} \mu \mathrm{CT}$-analysis, the region mostly affected by tensile strain is of the same size as the tip radius. Due to the fact that load was the same in the three tests, the tip with the small radius will cause the comparably largest penetration depth, with strain concentrated to a relatively narrow region close to the tip. This will facilitate cracking in mode I and the associated 
fiber separation, likely resulting in the numerous and dramatic fiber separation that occurs when using the

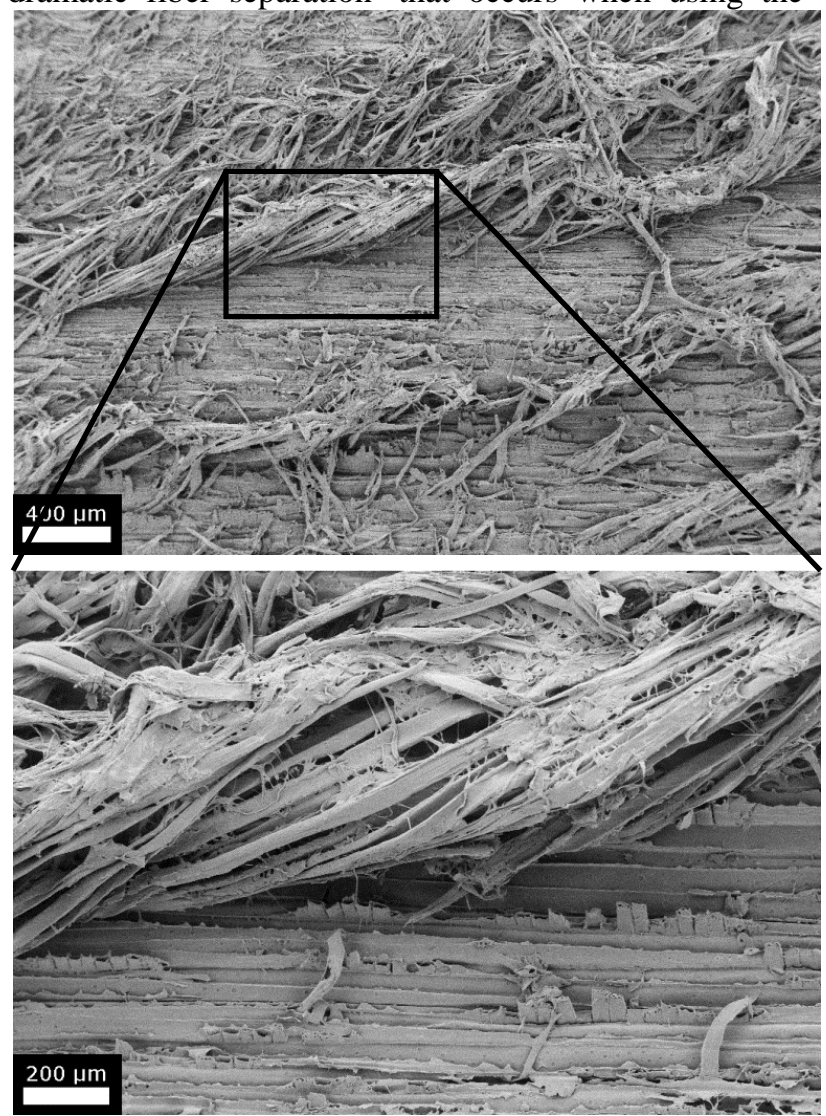

Fig 8 - The surface of a ground log, extracted from a Swedish pulp mill and saved from becoming fully processed into pulp.

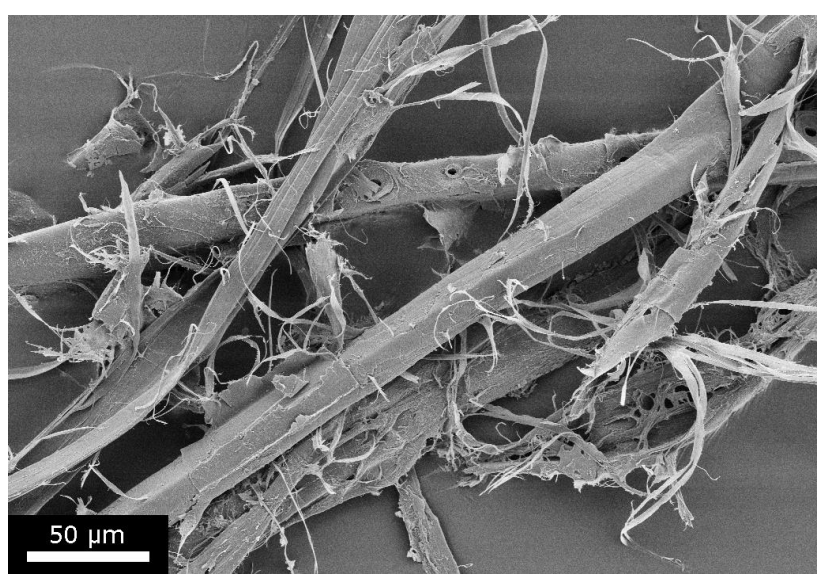

Fig 9 - Groundwood pulp fibers extracted from a Swedish pulp mill.

smallest radius. However, this local deformation is also the reason for the large amount of undesirable fiber cutting in these tests. Using larger radii will give rise to more distributed strains and a smaller amount of surface cracking. That allows other mechanisms, like sub surface shear cracks and curling of fibers to become visible.

The apparent absence of fiber cutting in industrial grinding, perhaps suggests that the mechanics in industrial defibration is better described as a fatigue process rather than rapid crack initiation and growth. In that light the shallow strain field that develops in the single asperity contacts imaged in $\mathrm{X} \mu \mathrm{CT}$ is especially interesting. The tip geometry could possibly be tailored to control the depth to which large tension is induced. It should also be noted that the styli used in this work all have spherical tips and the contact is very mild in comparison with the sharper features of a standard abrasive grit. Even though the geometries differ, the images of our scratched wood and the wood from the pulp mill show similarities, which is why we believe that this method should be further used to investigate the defibration.

At room temperature the fibers behave less flexibly and tend to be cut more frequently and to separate less. The low temperature also hinders the subsequent relaxation, which is why low temperature scratching results in both local and permanent deformation. The reason for this is largely that room temperature is not sufficiently high for softening of the lignin that holds the fibers together.

To be able to separate fibers completely from a piece of wood, multiple contacts are needed. We studied only the effects of the initial 20. In Fig 7 an increase in fiber separation can be seen as the number of scratches in the same position increases, but only at the expense of increased fiber cutting. This could indicate that larger tip radii or lower loads need to be used to simulate the industrial process where asperities might pass a single fiber a large number of times before the fiber is removed. However, there is also an effect of scratch position in industrial grinding that is neither explored nor exploited in this work. As previously stated, at the surface of the industrial grinding wheel, the abrasive grits are randomly distributed which, from a fiber point of view, means the point of attack will never be in exactly the same location. We believe that this variation of scratching position could also be one crucial parameter to tailor when optimizing tools; instead of a random grit position a well ordered structured surface could actually be more efficient.

The deformations found in scratching can be regarded as the initial stage of industrial defibration. Wood surfaces exposed to scratch testing do indeed show some similarities with those from the industrial grinding process. Minute defibration occurs in scratching and there are even tendencies of curling of fiber bundles, just as in industrial grinding. However, during scratch testing there are also lots of fiber cutting taking place. Cutting might occur also in industrial defibration, cf. Figs 8 and 9, although longer fibers are the norm.

\section{Conclusions}

- When a tip is pushed into wood, the deformation field in wood is significantly larger than what is expected from the classical continuum theories. The region of high tensile strains, where mode I cracks may open, is located at a shallow depth some distance away from the tip in contrast to in the Hertz theory where they are located close to the contact's edge. The region of high shear strains, linked to initiation and growth of mode II cracks, is substantially larger, compared to the theoretical field, and located more than two times deeper down in the material. These important observations on altered strain fields suggest that the scratch tip geometry, penetration depth and/or direction can be designed to control the defibration process. 
- Laboratory scale scratch testing can be used to mimic the early stage of defibration and to reproduce some of the mechanisms occurring industrially.

- A high temperature is necessary for any test trying to simulate the defibration mechanisms occurring industrially. Performing scratching at low temperature limits the fiber deformation and relaxation and hinders the test to imitate industrial defibration.

- Repeated scratching at the very same position on a fiber is not suitable for mimicking industrial defibration where abrasive tips contact the wood randomly at different positions.

\section{Acknowledgements}

Financial support from The Swedish Energy Agency is acknowledged.

\section{Literature}

Atack, D., Tabor, D. (1958): The friction of wood. Proc. R. Soc. London Ser. A, 246, 539-555.

Blaber, J., Adair, B., Antoniou, A. (2015): Ncorr: OpenSource 2D Digital Image Correlation Matlab Software. Exp Mech. 55(6), 1105-1122.

Björkqvist, T., Lucander, M. (2001): Grinding surface with an energy-efficient profile. Int. Mech. Pulping Conf. Helsinki, Finland, 373-380.

Dornfeld, D. A., Wu, S. M. (1977): An investigation of ground wood surfaces as related to pulp and stone characteristics. Wear, 42(1), 163-175.

Dornfeld, D. A. (1981): Single grit simulation of the abrasive machining of wood. J. Eng. Ind. - T. ASME, 103, 1-12.

Enström, E., Fagerhed, J-A., Lönnberg, B. (1990): Effects of pulpstone grtis in wood grinding. Part 1. Distribution of singlesize grits. Paperi Puu, 72(4), 385-390.

Isaksson, P. Ståhle, P. (2002): Prediction of shear crack growth direction under compressive loading. Int. J. Fract., 113(2), 175-194

Isaksson, P., Hägglund, R. (2013): Crack-tip fields in gradient enhanced elasticity. Eng Fract Mech, 97, 186-192.

Johnson, K.L. (1985): Contact Mechanics. UK: Cambridge University Press

Karinkanta, P., Illikainen, M., Niinimäki, J. (2011): The effect of anisotropicity of Norway spruce (Picea abies) during twobody abrasion. Wear, 272(1), 38-42.

Lucander, M., Lönnberg, B., Haikkala, P. (1985): The effect of stone surface modification on groundwood properties. J. Pulp Paper Sci., 11(2), 35-41.

Lucander, M., Björkqvist, T., Tuovinen, O. (2010): Method and apparatus for mechanical defibration of wood. US 7,819,149 B2, Oct. 26, 2010

Lönnberg, B., Finell, M., Gros, G. (1996): Basic study of pulpstone dullness. Pulp Paper Can., 97(10), 341-344.

Lönnberg, B., Lind, T., Tuovinen, O. (2006): Frictional phenomena in mechanical wood grinding. Cell. Chem. Technol., 40(9-10), 755-760.

Lönnberg, B., Lind, T., Touvinen, O. (2007): Frictional Impulse in Mechanical Wood Grinding. Int. Mech. Pulping Conf Minneapolis, USA.
Sandås, E., Lönnberg, B. (1990): Effects of pulpstone grtis in wood grinding. Part 2. Two-size grit mixture (various proportions). Paperi Puu, 72(8), 765-771.

Sandås, E. (1991): Effects of pulpstone grtis in wood grinding. Part 3. Two-size grit mixture (various sizes). Paperi Puu, 73(7), 641-650.

Sandås, E. (1991): Effects of pulpstone grtis in wood grinding. Part 4. Concluding discussion. Paperi Puu, 73(9), 858-864.

Sjöström, E. (1993): Wood chemistry: fundamentals and applications. $2^{\text {nd }}$ ed. New York: Academic Press.

Steenberg, B., Nordstrand, A. (1962): Production and dissipation of frictional heat in the mechanical wood grinding Process. Tappi, 45(4), 333-336.

Tuovinen, O., Fardim, P., Lönnberg, B. (2008): An investigation into topographic changes in pulpstone grits and their impact on pulp quality during the stabilization process. Paperi Puu, 90(7), 38-43.

Tuovinen, O., Fardim, P., Wiinamäki, A. (2009): Initial fiber effects in pressurized grinding as analysed by SEM. Int. Mech. Pulping Conf. Sundsvall, Sweden, 111-116.

Tuovinen, O., Björkqvist, T., Fardim P. (2013) Reconstruction and characterization of grinding wheel and grit topography from scanning electron microscopy stereo micrographs with digital photogrammetry. O Papel, 74(4), 51-58.

Tuovinen, O., Fardim P. (2015): Interrelation between grit morphology and defibration performance in pressurized groundwood process. O Papel, 76(10), 83-89.

Uhmeier, A., Salmén. L. (1996): Repeated large radial compression of heated spruce. Nord. Pulp Pap Res. J., 11(3), $171-176$

Manuscript received December 22, 2015 Accepted June 2, 2016 